\title{
"Barro na mão do oleiro": materialidades e sensibilidades na interface entre ensino de História e educação profissional
}

"Clay in the Potter's hand": materialities and sensitivities at the interface between teaching History and professional education

\author{
André Luiz Bis Pirola* \\ Juçara Luzia Leite ${ }^{* *}$
}

Resumo

Este artigo tem por objetivo analisar a interseção entre Ensino de história e Educação Profissional como via significativa para a superação de dualismos educacionais. A partir de estudos da história cultural que evocaram a noção de materialidade, propõe-se uma reflexão que dá ênfase à indissociabilidade entre as condições formais, tecnológicas, materiais e aos sentidos múltiplos elaborados pelos sujeitos históricos que intervêm em tais condições. Nesse sentido, o artigo demonstra como ensino e história, contanto que atentos às materialidades e sensibilidades, constituem dimensões imprescindíveis ao entendimento das lutas entre práticas e representações, formas e reformas que pretendem limitar as possibilidades da educação profissional e a própria possibilidade de transcender tais limitações. Palavras-chave: ensino de História; educação profissional; materialidade.

\section{Abstract}

This article aims to analyze the intersection between history teaching and professional education as a significant means of overcoming educational dualisms. From studies of cultural history that evoked the notion of materiality, it proposes a reflection that emphasizes the indivisibility of the formal, technology and materials conditions and the multiple meanings given by the historical subjects that influence in such conditions. In this sense, the article demonstrates how education and history attentive to the materiality and sensitivity are essential dimensions to the understanding of the struggles between practices and representations, between the forms and reforms to limit the possibilities of education and the possibility of transcending such limitations.

Keywords: History teaching; professional education; materiality.

\footnotetext{
* Doutor em História da Educação pela Pontifícia Universidade Católica de São Paulo (PUC-SP). Professor de História no Instituto Federal de Educação, Ciência e Tecnologia do Espírito Santo (IFES). Nova Venécia, ES, Brasil. andrepirola@ifes.edu.br

** Doutora em História Social. Pós-doutorado em História Política. Professora da Universidade Federal do Espírito Santo (UFES/PPGHis/PPGE). Pesquisadora Fapes. Vitória, ES, Brasil. jucara. leite@ufes.br
} 
"Barro na mão do oleiro" - foi com essa imagem que o professor e tipógrafo Jan Tschichold evocou a tipografia unindo coisas e sensibilidades (Tschichold, 2007, p.25). Modelar ideias a partir de tipos, tornear fontes e formas, levar à fornalha designs e desejos. Tais desafios formaram a obsessão de Tschichold por toda sua vida.

A imagem é também conveniente à análise de algumas pesquisas situadas entre a Educação e a História, estudos que analisam as condições formais, tecnológicas e materiais de seus objetos e que se apropriam da noção de materialidade ao se dedicarem às coisas, aos manuseios, aos artífices. Propomos, aqui, a contextualização da noção de materialidade na interseção do Ensino de História e da Educação Profissional, visando a refletir também sobre as sensibilidades imprescindíveis nessa relação.

Tanto na Educação quanto na História, não é raro o emprego e supressão de noções provenientes de outros campos - fenômeno compreensível, se considerada a convergência e divergência entre conhecimentos, se observada a contração e expansão de espaços de saber e poder. Nesses campos, há algum tempo, estudos ligados ao social e ao cultural assumiram contorno mais nítido, enquanto outros, prestigiados pela tradição do político e do econômico, em parte, buscam ressignificar suas interpretações frente aos desafios lançados pela contemporaneidade.

Novas posturas frente ao conhecimento tornaram mais complexos os sentidos da realidade e propuseram captar as experiências por múltiplos sujeitos e peculiares objetos: escola, professor, alunos, práticas escolares, materiais didáticos ganharam visibilidade e demandaram diferenciadas relações teórico-metodológicas. Trata-se de uma encruzilhada epistemológica que, sinalizada por elementos da Nova História Cultural e da Antropologia Cultural, possibilitou à Educação investigar realidades educacionais e/ou culturas escolares.

Para Chartier (1990; 2002; 2009) - propositor de um esquema conceitual que articula objetos culturais, representações culturais, práticas culturais, comunidades de interpretação e apropriação ${ }^{1}$-, há uma centralidade no conceito de cultura, compreendido à luz de Geertz:

um padrão de significados transmitido historicamente, incorporado em símbolos, um sistema de concepções herdadas expressas nessas formas simbólicas, por meio das quais os homens comunicam, perpetuam e desenvolvem seu conheci- 
mento e suas atividades em relação à vida. (Geertz, 1973, p.89 apud Chartier, 2009, p.35)

É, pois, interessante que, justamente no seio de proposições teóricas prenhes de símbolos, representações, sistemas de concepções e formas simbólicas, construam-se estudos cujas vigas mestras erguem-se sobre a concretude da materialidade. Vislumbramos três pontos de convergência desses estudos que, segundo nossa compreensão, tratam a:

1. Materialidade como apreensão das condições formais;

2. Materialidade como apreensão das condições tecnológicas;

3. Materialidade como apreensão das condições materiais.

Tais pontos de convergência são compreendidos por nós como lugares de afinidades, não somente como esforço classificatório. São, portanto, espaços nos quais abordagens, ainda que diversas, formam um conjunto coerente. Além disso, ao delimitar essas convergências, não é nosso objetivo confiná-las a esses limites, mas destacar a possibilidade de abordagens complexas, passíveis de serem situadas em diferentes (ou todos) pontos simultaneamente.

Acreditamos, assim, que os pontos de convergência aqui anunciados agregam abordagens que captam a historicidade de seus objetos e, mesmo constituídos a partir de diferenciadas apostas metodológicas, almejam apreender sua inteligibilidade histórica. Para exemplificar nossa reflexão, vamos nos ater, por enquanto, à materialidade do impresso.

\section{MATERIALIDADE COMO APREENSÃO DAS CONDIÇÕES FORMAIS}

No âmbito dos pontos de convergências, pesquisadores dedicados à História do Livro, do Livro Didático e dos Impressos Pedagógicos têm sido pródigos em apresentar trabalhos bem-sucedidos. Roger Chartier e Daniel Roche (1976, p.100) já evocavam uma "bibliografia material" adequada para se realizar uma história do livro, sob novas perspectivas. Propunham assim transformar antigas paixões em objetos de pesquisa, captar as marcas materiais dos objetos impressos em um conjunto maior, dar inteligibilidade às realidades históricas. 
O mesmo Chartier (1998, p.8) dedicaria adiante alguma atenção aos dispositivos técnicos, visuais e físicos que organizam a leitura escrita transformada em livros - ou seja, posta em ordem. Propósito similar ao de Robert Darnton (1990, p.109) quando, ao seu modo, o autor busca entender como as "ideias eram transmitidas por vias impressas e como o contato com a palavra impressa afetou o pensamento e comportamento da humanidade nos últimos quinhentos anos". Darnton crê na possibilidade de o entendimento das ideias transmitidas propiciar melhor conhecimento dos ideais por detrás da leitura no passado. A bibliografia analítica é uma das modalidades enumeradas pelo pesquisador: os livros enquanto objetos físicos podem demonstrar que a disposição tipográfica tem efeitos reveladores e significativos sobre a forma como um texto foi lido.

Tais proposições nos remetem aos desafios da formação considerada "técnica”. Formação técnica aqui entendida como partícipe dos desafios enfrentados pelos profissionais de Ensino de História frente aos saberes e práticas que abrangem outras áreas de conhecimento, sobretudo as dos cursos "técnicos", que constituem o universo da educação profissional nas instituições escolares em que tais profissionais atuam.

Daí se deve um primeiro retorno, atento e esmerado, por parte dos profissionais do ensino de História à dimensão histórica de fenômenos como a profissionalização, os profissionais. Bem como sua atenção dispensada aos saberes "técnicos", que, na própria tradição formativa dos cursos superiores de História, foram considerados, frequente - e preconceituosamente - como "auxiliares".

Nesse sentido, decisivos à acurada compreensão dos registros, os conhecimentos em Paleografia, Bibliografia, Codicologia - mas também, como ratificou Munakata (1997, p.79) em tipografia, composição, diagramação, editoração, refilamento, acabamento - compõem a esfera das "ciências ocultas". Saberes que se revelam plenamente somente no transcorrer de anos de profissão e fazem, portanto, toda a diferença quando os traços só se mostram inteligíveis àqueles que compartilham seus códigos de constituição.

Cada vez mais oportuno ao Ensino de História na Educação Profissional seria assim, justamente, esse retorno aos conhecimentos que remetem a uma determinada materialidade, ou a uma formação "técnica" que permita a apreensão das condições formais, dos suportes materiais por meio dos quais 
as experiências são dadas à leitura. As possibilidades formativas são muitas. Por exemplo: propiciar uma apropriação mais significativa das ideias que, historicamente, constituíram as coisas. Porém, com a decisiva diferença de se partir das próprias coisas com as quais interagimos; explicitar que as coisas, os objetos, as máquinas, as práticas, em sua constituição e disposição física - em sua materialidade -, trazem as marcas de uma historicidade oculta, que pode ser subvertida a partir de muitas outras leituras que a confrontem; ampliar a percepção do modo como os elementos aparentemente neutros e técnicos propõem, muitas vezes, de fato, um "roteiro de leitura" na produção das ideias e práticas, afetando e construindo sensibilidades, produzindo o real.

Nesse sentido, Moura (2008, p.28), tratando da formação no âmbito da Educação Profissional, explicita a responsabilidade social desse campo, tendo em vista tanto os profissionais que lecionam quanto o público para o qual se leciona. O autor remete, assim, à capacidade de inserção e reinserção social, laboral e política de seus formandos, referindo-se também à formação integral dos coletivos que "procuram a escola pública de EPT para que esses sujeitos possam atuar, de forma competente e ética, como agentes de mudanças orientadas à satisfação das necessidades coletivas, notadamente as das classes trabalhadoras".

\section{Materialidade COMO APREENSÃo DAS CONDIÇÕES TECNOLÓGICAS}

Propor, no sentido acima descrito, uma história das técnicas e dos atos físicos que se vinculam aos procedimentos técnicos - "uma história do traçado" - é também a profícua investida de Armando Petrucci (1999). Mais que enumerar técnicas constituintes dos processos de confecção dos artefatos literários, Petrucci procede ao delicado relacionamento entre o imponderável e ponderável - aos gestos e gênios que se enlaçam na constituição dos testemunhos escritos.

$\mathrm{O}$ autor evoca a importância de se deter, por exemplo, sobre os gestos dispensados a cada operação; sobre a relação entre o visual e o físico; sobre os espaços de trabalho e a posição dos corpos que os ocupavam; sobre a questão de se saber quem faz, o que se faz, como se faz, e o feito. Em outras palavras, "coisificar" signos e, inversamente, significar "coisas". 
Foi seguindo tal perspectiva que Walter Ong (1998, p.107), ao afirmar que "todo registro escrito representa palavras como se de algum modo elas fossem coisas, objetos mudos, marcas imóveis para assimilação pela visão", relacionou oralidade e cultura escrita, tornando assim manifesta a estreita relação existente entre uma tecnologia de escrita rebelde (blocos de barro molhado, peles de animais, cascas de árvores) e hábitos mentais (1998, p.111-112). Porém, não estava sozinho. Antes de Ong (1998), Clanchy (1979) apontara o vínculo entre procedimentos e conhecimentos, e Goody (1988), antes de ambos, previra a domesticação e resistência do pensamento selvagem em face de práticas e convenções de uma cultura escrita que age sobre a cognição daqueles que com ela travavam contato.

Exemplos não faltam...

No entanto, a obviedade de alguns deles constitui o próprio óbice ao aprofundamento de muitas pesquisas - é o que denuncia Elizabeth Eisenstein (1998). Para a pesquisadora, parece ser tão transparente a relação entre maior afluxo de livros e maior interesse pela leitura, maior quantidade de periódicos científicos e maior produção de saber, maior circulação de impressos e maior circulação de ideias, que os pesquisadores predominantemente não se debruçam sobre tais fenômenos.

Conjugando disseminação, padronização, catalogação, adulteração e preservação, Eisenstein sugere que tais elementos promoveram novas formas de ler impressos, de comunicar saberes, de ver índices, de pesquisar autos, de captar ideias - novos sentidos. E isso não é pouco.

Não podemos desconsiderar, portanto, os questionamentos que tais abordagens metodológicas podem trazer às práticas de Ensino de História no âmbito da Educação Profissional. Afinal, não seria uma possibilidade ímpar promover uma experiência educacional na qual estudantes fossem instigados a compreenderem, a partir das próprias práticas profissionais que a instituição lhes oferece, os procedimentos e representações que se enlaçam historicamente na constituição dessas mesmas práticas?

Ora, foi justamente buscando essa experiência educacional instigadora e integrada a seu próprio mundo do trabalho que, em 23 de julho de 2004, o Decreto $\mathrm{n}^{\circ}$ 2.208/97, que dualizava o ensino médio e técnico brasileiro, foi revogado por uma nova proposta de governo e educação, expressando-se, então, por meio do Decreto no 5.154/04, um novo caminho na intercessão de 
saberes. O que criava, por sua vez, uma concepção diferenciada para o seu ensino. Talvez tenha sido por estar imersa nesse sentido de integração que a pesquisadora Vera Bressan tenha apontado que

No processo de elaboração do Decreto 515/04, sua proposta visaria à restituição da possibilidade de integração entre Ensino Médio e Profissional (EM e EP), com a intenção de assegurar o acesso aos princípios e fundamentos científicos e tecnológicos do trabalho na formação dos trabalhadores, tendo em vista uma concepção emancipatória de formação. (Bressan, 2006, p.59)

Qual não seria, então, o ganho para o Ensino de História em aprofundar a compreensão histórica dos elementos, dispositivos e instrumentos profissionais, ressignificando-os como se fossem - e como de fato são - coisas, objetos e marcas, relacionando-os à oralidade e cultura escrita dos estudantes, explicitando, ainda, o quão sutil, poderosa, perigosa ou promissora pode ser a relação entre tecnologias e hábitos mentais que dão suporte às práticas?

Parece-nos também óbvio, mas não natural, o quanto podemos aprender e ensinar, considerando, na duração, a intencionalidade e o quantum dos afluxos, circulações e distribuições de dados materiais, máquinas e equipamentos, bem como a maior produção impressa de determinados saberes especializados - e não outros -, interessando-se, assim, por práticas desinteressadas de disseminação, padronização, catalogação e adulteração dos componentes constitutivos de uma área profissional.

Um ganho significativo no que chamaremos, aqui, de estudos em materialidade como apreensão das condições tecnológicas talvez seja propor um novo sentido teórico metodológico à apreensão das realidades profissionais. Sensibilidade que amplia a noção de materialidade por contemplar as condições formais, as condições tecnológicas e as condições materiais como fiadoras privilegiadas da historicidade dos sujeitos e objetos investigados.

\section{MATERIALIDAdE COMO APREENSÃO DAS CONDIÇÕES MATERIAIS}

Foi tendo em vista tal apreensão que o antropólogo Adam Kuper (2002) criticou a produção do senso comum que utiliza o conceito de cultura necessariamente como explicador e não como aquilo que deve ser explicado. 
Questionando as próprias pretensões da teoria cultural, Kuper alerta ser fundamental não desconsiderar ou subestimar instituições sociais, processos biológicos e forças políticas e econômicas. Segundo o antropólogo, o conceito de cultura, imerso em uma "hiper-referencialidade", passa a ser, muitas vezes, o próprio complicador de questões que, em geral, são muito específicas e urgentes. Para entendermos os perigos da aplicação deliberada do conceito,

basta considerarmos alguns fatores que ele rejeita: as consequências das políticas econômicas, o poder modelador da política internacional, a política dos grupos de interesses ... talvez devamos passar a falar de forma mais precisa sobre conhecimento, conviç̧ão, arte, tecnologia, tradição ou até mesmo ideologia. (Kuper, 2002, p.9-12)

Pensando o Ensino de História e a Educação Profissional, esse projeto evoca muito daquilo que Fernand Braudel (1970) quis captar quando escreveu Civilização Material, Economia e Capitalismo, propondo a leitura do mundo dos séculos XV ao XVIII e esforçando-se por considerar os "Jogos das trocas" imersos na economia de mercado e capitalismo, a tensão dos antagonismos e desigualdades que essas duas dimensões produzem.

Há, portanto, alguns estudos em materialidade restritos a uma noção de mercado que permeia, afeta e impregna os modos de ser/fazer. E, aqui, talvez seja importante esclarecer que não concebemos qualquer força apriorística e sub-reptícia que objetiva sufocar políticas culturais e/ou educacionais. Ao contrário, se existem tenazes desequilíbrios na realidade é porque existem, também, vazios perigosos deixados pelas instâncias criadas pelos homens e pelos demandantes da regulação da existência desses mesmos sujeitos. A realidade explicita contradições: modos de produzir sequestram a inventividade do ser humano, desconsiderando o próprio homem; agregam valor aos produtos (tornando-os cada vez mais necessários), desagregando trabalhadores (tornando-os cada vez mais supérfluos); prometem a liberdade, constituindo-se em dispositivo de controle. Porém, se tudo isso ocorre, não ocorre à revelia dos sujeitos históricos.

Munakata (1997) alertou para o fato quando, tratando da produção e profissionalização do mercado de livros didáticos e paradidáticos, analisou sua dimensão em face das ações do Estado brasileiro. É interessante refletir com o 
pesquisador - quando questiona as próprias críticas à indústria cultural - que, muitas vezes, o que é demonstrado, de fato, não é a

natureza essencialmente corrompida dessa indústria; apenas o que acontece quando não se trabalha direito. O livro didático ruim, malcuidado, cheio de erros e preconceitos, ocorre, não por causa da indústria cultural, mas onde ela falha. A busca do lucro não tem como corolário necessário um produto ruim. Muito menos um sistema de ensino que faz minguar a dignidade do professor ... Não adianta tampouco reclamar que nele os conteúdos se petrificam, impossibilitando a reflexão crítica. Qualquer texto, por mais malabarismo dialético que possa executar, acaba se cristalizando em tinta e papel: afinal, livro é coisa. O que se faz com coisa é uma outra história. (Munakata, 1997, p.202-203)

E as coisas que implicam Ensino de História na Educação Profissional transcendem os próprios portões das escolas e dos países, imbricando-se, então, em processos globais que se desenvolvem em projetos econômicos e projeções culturais. Coisas desveladas por Célia Cassiano (2007) quando da análise da entrada do Brasil no mercado editorial ibero-americano do capital econômico e cultural espanhol a partir das políticas de abertura propostas pelo governo brasileiro. A compreensão histórica da política econômica, não necessariamente cultural, no processo de entrada de capitais específicos para áreas específicas do mundo do trabalho pode elucidar muitas coisas nos cursos técnicos das instituições escolares.

Consoante com o que propusera Kuper (2002), e tecendo uma complexa teia cujos pontos de interesse são trançados de forma muito bem definida, o Ensino de História na Educação Profissional nos convida a repensar metodologicamente classificações demasiado ingênuas, segundo as quais investidas econômicas, políticas e culturais se dão em dimensões estanques. Ao contrário, tal ensino não reduz a complexidade da realidade a um de seus aspetos - seja qual for - mas trata, justamente, de, fugindo da "hiper-referencialidade" do conceito de cultura, "ampliar a questão para as dimensões da cultura e da educação do Brasil no mundo globalizado" (Cassiano, 2007, p.207). 


\section{QUANDO O ALUNO É O OLEIRO}

De um modo geral, a reflexão sobre a Educação Profissional no Brasil, não obstante as proposições sobre materialidade e sensibilidades aqui propostas, ainda se debate com reducionismos, apresentando-a por tecnicismos que persistem na própria noção de formação profissional. Essa prática não condiz com o discurso presente em diferentes diretrizes para a educação profissional, para os quais a ideia de uma formação crítica e reflexiva desse futuro profissional mostra-se como algo novo, como por exemplo:

O Ifes deve cumprir seu papel social, de contribuir para uma sociedade sem pobreza socioeconômica e sem degradação ambiental, mais autônoma e solidária, principalmente em virtude das transformações e diversidades do mundo contemporâneo.

Considerando essa premissa a educação profissional não prescinde do conhecimento reflexivo, ao contrário, deve desenvolver-se em um contexto envolto de conhecimentos, princípios e valores que potencializam a ação humana na busca de caminhos mais dignos de vida.

Dessa forma as políticas para a educação profissional e tecnológica posicionam-se para além do fator econômico, buscando por meio da integração e da articulação entre ciência, tecnologia, cultura e trabalho e do desenvolvimento da capacidade de investigação científica, elementos essenciais para as vertentes educação e trabalho, em busca de novas políticas de inclusão e transformação social pelas quais se elimine a pobreza socioeconômica sistêmica e se garanta a preservação da natureza. ${ }^{2}$

Souza (2010) já advertia que:

Pensar a escola como capaz de formar cidadãos ativos e críticos parece ser uma ideia recente no contexto da educação brasileira. As propostas pedagógicas atuais buscam enfatizar a importância da escola para formar alunos que compreendam o significado de cidadania e sejam capazes de fazer uso dela. Contudo essa percepção da escola como instrumento para a formação de cidadãos é uma ideia que há muito foi defendida pelo teórico italiano Antonio Gramsci. (Souza, 2010, p.16) 
Pensamos que, apesar dos discursos, tal prática é legitimada e decorre do trato atemporal da noção de Educação Profissional. Esse tratamento inviabiliza a superação do dualismo presente na Educação Profissional entre academicismo e profissionalismo e torna-se a base de sustentação de uma formação claudicante cujo produto é um profissional alienado de seu trabalho (Kuenzer, 1989). Concordamos, portanto, com Souza (2010) quando ele conclui que:

O trabalho como princípio educativo articula o trabalho intelectual e o produtivo e é uma proposta defendida por diversos autores vinculados ao ensino. Está voltado para uma formação mais humana, percebendo a categoria trabalho enquanto atividade social e intelectual na tentativa de superar a subordinação alienada ao capital. (Souza, 2010, p.23)

Acrescentamos uma observação sobre a necessária reflexão (que não é objetivo deste artigo) sobre as diretrizes, currículos, propostas, programas e legislações que regem o Ensino Profissional atualmente, uma vez que esses textos interferem diretamente nas práticas e culturas escolares. A própria ideia de profissão presente nos documentos que subsidiam o Ensino Profissional é reveladora de representações historicamente construídas.

Defender, pois, a necessária historicização das práticas e representações que subjazem a cada formação profissional é uma das dimensões proporcionadas pelo Ensino de História na Educação Profissional e oferece respostas a uma questão comum aos colegas docentes na Educação Profissional, que se limitam a compreendê-la como formação tecnicista e mercadológica: o ensino de história vem a quê? Compreendemos que vem a construir um sentido e significado próprios às práticas e às condições materiais daquela profissão e daquele profissional em formação. A construir um sentido e significado daquele trabalho e, dessa forma, transcender uma imposição que ali se instalou historicamente.

De modo geral, o Ensino de História na Educação Profissional é realizado sem vínculo com os objetivos profissionalizantes e resume-se a uma lista de conteúdos factuais tradicionais, discriminados segundo conteúdos específicos sob a denominação de conteúdos de formação geral. Entretanto, o conteúdo não deve ser lido fora do suporte no qual é dado a ler. Se a Educação Profissional pode ser percebida como suporte, o conteúdo do Ensino de História deve aí estar inserido. E que História é essa? A História das materialidades que 
dão forma a essa ou àquela profissão conferindo-lhes a dignidade do trabalho humano. Essa materialidade específica surgiu de uma demanda histórica, conforme nos conta o exemplo das reflexões que tecemos a partir da História dos Impressos.

Para Souza (2010):

O foco do ensino na atualidade está no aprendizado e o que ele significa para o aluno. Isso não significa que devemos descartar os conteúdos, mas reformular seus conceitos e aliá-los à prática da aprendizagem, pois os problemas não são os conteúdos, e sim o modo como são ensinados e como são aprendidos; eis o ponto de partida para a aprendizagem significativa.

O ensino de História, se devidamente articulado com esse pensamento, pode ir além de uma História que se preocupa unicamente com fatos e poderá se incorporar à vida prática dos envolvidos nesse processo, proporcionando ao aluno do século XXI maior compreensão e participação no seu processo de aprendizagem, atribuindo sentido a ele. (Souza, 2010, p.76)

Compreendemos, portanto, que a História das práticas profissionais está relacionada a materialidades específicas, mas também ao embate por representações dessas práticas e dessas profissões. Desvendar a História a partir do que é dado ao aluno como formação específica, como representação da profissão, é um trabalho de engenharia reversa, de decodificação.

Pensamos, assim, tratar-se de uma decodificação histórica das máquinas, práticas, representações e demandas reais atravessadas por dores e sentimentos específicos, não apenas interesses mercadológicos. Uma história das técnicas e das máquinas que considere as sensibilidades não é um triunfo da inteligência, mas um testemunho que traz, em sua materialidade, indícios e vestígios do trabalho que foi, que ali ainda está. É um trabalho de história e arqueologia feito a partir de testemunhos materiais e que rompe com uma concepção simplista e linear da História e de seu ensino.

Dessa forma, não basta destacar os conteúdos de ensino que contemplem essa ou aquela abordagem, mas sim garantir formação de professores que percebam alternativas frente aos desafios contemporâneos. A materialidade como apreensão das sensibilidades é uma possibilidade que apresentamos. 
Se a Educação Profissional é como o barro, o aluno é o oleiro. Um Ensino de História que confira sentido e significado pode indicar os contornos que promovem a vida.

\section{MATERIALIDADE COMO APREENSÃo DAS SENSIBILIDADES?}

Este é um viés que sugerimos como possibilidade. De fato, é cada vez mais explorado por pesquisadores de variadas áreas e aponta para os modos de sentir. Um movimento que - a exemplo da metáfora evocada por Tschichold - dá visibilidade e molda objetos, muitas vezes etéreos, fugazes ou fugidios, (im)propriedades que demandam formas diversas de abordagem metodológica. São, portanto, alternativas de compreensão do sentido, deslocamentos procedimentais à pesquisa das sensibilidades.

Todavia, não nos enganemos. Os objetos que investigamos podem ser imateriais, porém as fontes com as quais lidamos para apreendê-los são todas aquelas validadas e operadas pelo rigor historiográfico. Já estão disponíveis algumas contribuições há algum tempo e resgataremos aquelas mais estreitamente ligadas ao campo historiográfico.

É válido relembrar a propósito que, a partir do final dos anos 1960, a noção de mentalidade se impôs na historiografia francesa como oposição àquilo que designavam ideias ou fundamentos socioeconômicos. Se, por um lado, os estudos se afastavam assim de uma História Intelectual que isolava as ideias de seus contextos de produção e atribuía toda inventividade a personagens únicos, por outro associavam-se à Sociologia e à Psicologia na instauração de novas abordagens (Chartier, 2002, p.28-34). Observava-se também o distanciamento constante de alguns historiadores ante as quantificações, seriações e procedimentos historiográficos até então vigentes. Pode-se citar por exemplo "Concebido e Sentido, o Campo da Inteligência e do Afetivo" de Robert Mandrou (1961); "Sensibilidade” de Lucien Febvre (1965); "Maneiras de Sentir e de Pensar" de Marc Bloch (1979); ou, mais recentemente, a "Educação dos Sentidos” de Gay (1988) e os “dispositivos afetivos” de Alain Corbin (2000).

Para além das propostas que captam as sensibilidades a partir das narrativas, podemos propor outras que captem as sensibilidades a partir da materialidade dos objetos investigados na Educação Profissional. Discussões e pesquisas que utilizam a noção de cultura material escolar têm trazido, nesse 
sentido, interessantes contribuições. De acordo com Bucaille e Pesez (1989) citados por Veiga (2003, p.2), "um dos primeiros sinais de avanço dos estudos nessa área localiza-se ao longo do século XIX, através das rupturas feitas com a arqueologia clássica". Segundo a pesquisadora, desenvolveu-se a produção de novas sensibilidades que transcenderam a contemplação dos objetos, buscando relacioná-los com seus respectivos contextos. Logo, os avanços dos estudos da cultura material estiveram também ligados aos avanços da própria arqueologia.

Quando um texto cita um objeto concreto, não se pode, na maior parte dos casos, dar dele uma imagem precisa; a arqueologia, pelo contrário, põe-nos diretamente em contato com o próprio material, que se pode tocar, examinar e interpretar sem o perigo de erro devido à subjetividade da documentação. (Bucaille; Pesez, 1989, p.19 apud Veiga, 2000, p.2)

Vidal e Silva (1995), citados por Dutra (2001), por exemplo, "veem os objetos da cultura material como resultantes da experiência da vida cotidiana e como formadores e identificadores das identidades dos grupos". Conforme os pesquisadores citados:

Assim como formas expressivas da cultura e elementos de sistemas de comunicação, o sistema de objetos e as artes são produtos de uma história: remetem-se às tradições identificadas pelo grupo como suas marcas distintivas, específicas de sua identidade; falam dos modos de viver e de pensar compartilhados no momento da confecção do produto material ou artístico ou da vivência da dramaturgia dos rituais, indicando uma situação no presente; em suas inovações, no esmero de suas produções e no uso que dela fazem, indicam as relações entre o indivíduo e o patrimônio cultural do grupo a que pertencem. (Vidal; Silva, 1995, p.371, apud Dutra, 2001)

Cabe também ressaltar que os estudos acerca dos mediadores culturais e da mediação didática no processo de construção do conhecimento histórico pelo aluno têm promovido interessantes abordagens sobre a aprendizagem da História considerando a mediação de diferentes ferramentas culturais além da linguagem e do professor (Siman, 2004).

Para Menezes (2005, p.14), trabalhar com a materialidade da escola permite compreender a escola "como prática cultural, que se constitui na 
interseção de outras práticas culturais de nossa sociedade”. A pesquisadora enfatiza a necessidade de realizações como as do dossiê Cultura escolar e Cultura Material escolar: entre arquivos e museus, realizado durante o I Seminário sobre Educação e História, organizado em parceria com o professor Luiz Carlos Barreira, na Unicamp, em julho de 2003. Vidal (2005) também assim o entende quando do estudo dos elementos materiais escolares e sua relação com as estratégias e táticas na escola.

Certamente os desafios não são pequenos...

Aquilo que chamamos, aqui, de estudos em materialidade, é, de fato, um conjunto de tentativas interessantes para referenciar melhor as formas, as tecnologias, as condições e as sensibilidades que constituem os saberes e fazeres escolares. Pode até causar estranhamento propormos diversas abordagens metodológicas, no entanto, pensamos ser possível, a partir de tais e tantos câmbios, dar mais inteligibilidade às realidades construídas e vividas pelos sujeitos históricos. Propomos, assim, ir além de análises que, mutilando os contextos estudados, acabam por mutilar a possibilidade de compreensão dos mesmos, insistindo em pensar a realidade material como algo menor ou prescindível da apreensão dos objetos. Foi justamente contra toda uma tradição, vulgarmente retórica, que os estudos em materialidade dedicaram-se aos objetos e explicitaram seus objetivos. Pressupostos que vão ao encontro de

uma formação que permita o domínio das técnicas, das leis científicas e [da questão de se saber] a serviço de quem e de quantos está a ciência e a técnica. Trata-se de uma formação humana que rompe com as dicotomias geral e específico, político e técnico ou educação básica e técnica, heranças de uma concepção fragmentária e positivista de realidade humana. (Frigotto, 2005, p.74)

Assim, os exemplos apresentados ao longo do texto demonstram uma busca por associar ideias e coisas, pensando que, separá-las, seria epistemologicamente falso. Não são necessariamente trabalhos realizados por historiadores, mesmo porque foi com a diversidade das perspectivas que ganhamos em riqueza.

Finalmente, pensamos que, em uma Academia, muitas vezes repleta de relativismos perigosos e de apostas epistemológicas dissociadas da própria realidade, pensar a amplitude da materialidade é dar mais fidedignidade e 
credibilidade aos trabalhos que não dissociam a Educação da História, da Política e da Sociedade.

\section{REFERÊNCIAS}

BLOCH, Marc. A sociedade feudal. Lisboa: Ed. 70, 1979.

BRAUDEL, Fernand. Civilização material e capitalismo: séculos XV-XVIII. Trad. Maria Antonieta Magalhães Godinho. Lisboa: Cosmos, 1970.

BRESSAN, Vera. Educação Geral e Profissional: Ensino Integrado e as possibilidades da formação unitária e politécnica. Dissertação (Mestrado em educação) - Setor de Educação, Universidade Federal do Paraná (UFPR). Curitiba, 2006.

BUCAILLE, Richard; PESEZ, Jean Marie. Cultura Material. In: ENCICLOPÉDIA EINAUDI. v.16. Rio de Janeiro: Imprensa Nacional, 1989.

CASSIANO, Célia C. F. O mercado do livro didático no Brasil: da criação do Programa Nacional do Livro Didático (PNLD) à entrada do capital internacional espanhol (1985-2007). Tese (Doutorado em Educação) - Pontifícia Universidade Católica de São Paulo (PUC-SP). São Paulo, 2007.

CHARTIER, Roger. A aventura do livro: do leitor ao navegador. Conversações com Jean Lebrun. Trad. Reginaldo Carmello Corrêa de Moraes. São Paulo: Imprensa Oficial do Estado de São Paulo; Ed. Unesp, 1998.

. À beira da falésia: a história entre certezas e inquietude. Trad. Patrícia Chittoni Ramos. Porto Alegre: Ed. UFRGS, 2002.

A História Cultural: entre práticas e representações. Trad. Maria Manuela Galhardo. Lisboa: Difel; Rio de Janeiro: Bertrand Brasil, 1990.

. A história ou a leitura do tempo. Trad. Cristina Antunes. Belo Horizonte: Autêntica, 2009.

CHARTIER, Roger; ROCHE, Daniel. O livro: uma mudança de perspectiva. In: LE GOFF, Jacques; NORA, Pierre (Org.) História: novos objetos. Rio de Janeiro: Francisco Alves, 1976. p.99-115.

CLANCHY, Michael. From memory to written record. London: Edward Arnold, 1979.

CORBIN, Alain. Historien du sensible: entretiens avec Gilles Heuré. Paris: La Découverte, 2000.

DARNTON, Robert. O beijo de Lamourette: mídia, cultura e revolução. Trad. Denise Bottmann. São Paulo: Companhia das Letras, 1990.

DUTRA, Soraia F. Objetos da cultura material como mediadores no desenvolvimento do raciocínio histórico em crianças. In: PERSPECTIVAS DO ENSINO DE HIS- 
TÓRIA, 4., 2001, Campinas. Anais... Disponível em: http://ojs.fe.unicamp.br/ged/ $\mathrm{FEH} /$ article/viewFile/5446/4354.

EISENSTEIN, Elizabeth L. A revolução da cultura impressa: os primórdios da Europa Moderna. Trad. Osvaldo Biato. São Paulo: Ática, 1998.

FEBVRE, Lucien. La sensibilité et l'histoire. In: . Combats pour l'histoire. Paris: Armand Colin, 1965. p.221-238.

FRIGOTTO, Gaudêncio; CIAVATTA, Maria; RAMOS, Marise (Org.) Ensino Médio Integrado: concepção e contradições. São Paulo: Cortez, 2005.

GAY, Peter. A educação dos sentidos: a experiência burguesa da Rainha Vitória a Freud. São Paulo: Companhia das Letras, 1988.

GEERTZ, Clifford. A interpretação das culturas. Rio de Janeiro: Zahar, 1973.

GOODY, Jack. Domesticação do pensamento selvagem. Trad. Nuno Luís Madureira. Lisboa: Presença, 1988.

KUENZER, Acacia Z. O trabalho como princípio educativo. Caderno de Pesquisas, São Paulo, v.68, p.21-28, 1989.

KUPER, Adam. Cultura, a visão dos antropólogos. Bauru (SP): Edusc, 2002.

MANDROU, Robert. Introduction à la France moderne, 1500-1640. Paris: Albin Michel, 1961.

MENEZES, Maria C. A escola e a sua materialidade: o desafio do trabalho e a necessidade da interlocução. (Texto de apresentação). Pro-posições - Revista da Faculdade de Educação da Unicamp, Campinas, v.16, n.1, p.13-18, 2005.

MOURA, Dante H. A formação de docentes para a educação profissional e tecnológica. Revista Brasileira da Educação Profissional e Tecnológica, v.1, n.1, p.23-38, jun. 2008. Brasília: MEC/Setec, 2008. Disponível em: http://portal.mec.gov.br/setec/ arquivos/pdf3/rev_brasileira.pdf.

MUNAKATA, Kazumi. Produzindo livros didáticos e paradidáticos. Tese (Doutorado em História e Filosofia da Educação) - Pontifícia Universidade Católica de São Paulo (PUC-SP). São Paulo, 1997.

ONG, Walter. Oralidade e escrita: a tecnologização da palavra. Campinas: Papirus, 1998.

PETRUCCI, Armando. Ler por ler: um futuro para a leitura, In: CAVALLO, Guglielmo; CHARTIER, Roger (Org.) História da leitura no mundo ocidental. São Paulo: Ática, 1999. v.2, p.203-227.

SIMAN, Lana Mara de C. O papel dos mediadores culturais e da ação mediadora do professor no processo de construção do conhecimento histórico dos alunos. In: ZARTH, Paulo A. et al. (Org.) Ensino de História e Educação. Ijuí: Ed. Unijuí, 2004. 
SOUZA, Francinne C. de. Educação profissional: História e ensino de História. Dissertação (Mestrado em História) - Universidade Estadual de Londrina (UEL). Londrina, PR, 2010.

TSCHICHOLD, Jan. A forma do Livro: ensaios sobre estética e tipografia do livro. Trad. José Laurênio de Melo. São Paulo: Ateliê Editorial, 2007.

VEIGA, Cynthia G. Cultura material escolar no século XIX em Minas Gerais. In: CONGRESSO BRASILEIRO DE HISTÓRIA DA EDUCAÇÃO, 1., 6-9 nov. 2000, Rio de Janeiro. Anais... Rio de Janeiro: SBHE, CD 1, 2000. Disponível em: http:// www.sbhe.org.br/novo/congressos/cbhe1/anais/040_cynthia.pdf.

VIDAL, Diana G. Cultura e práticas escolares: uma reflexão sobre documentos e arquivos escolares. In: SOUZA, R. de F.; VALDEMARIN, V. T. (Org.) A cultura escolar em debate: questões conceituais, metodológicas e desafios para a pesquisa. Campinas: Autores Associados, 2005.

VIDAL, Lux; SILVA, Araci L. O sistema de objetos as sociedades indígenas: arte e cultura material. In: SILVA, Aracy L.; GRUPIONI, Luís D. B. A temática indígena na escola: novos subsídios para professores de $1^{\circ}$ e $2^{\circ}$ graus. Brasília: MEC/Mare; Unesco, 1995.

\section{NOTAS}

${ }^{1}$ Mosaico conceitual que se constitui, por sua vez, a partir de outras apropriações, como o conceito de outillage mental, em Lucien Febvre; o de representação coletiva, em Marcel Mauss e Emile Durkheim; os de táticas e estratégias, em Michel de Certeau; ou o de comunidades de interpretação, em Stanley Fish - dentre outros que remetem, por exemplo, a Elias, Foucault e Bourdieu.

${ }^{2}$ PDI/IFES. Disponível em: http://ifes.edu.br/images/stories/files/noticias/2014/02_ Fevereiro/ppi_janeiro_2014.pdf.

Artigo recebido em 18 de julho de 2016. Aprovado em 31 de agosto de 2016. 